\title{
The Effect of Temperature and Mean Cumulative Daily Light Intensity on Fruiting Behavior of Greenhouse-grown Tomato
}

\author{
Sezgin Uzun \\ The University of Ondokuz Mayls, Faculty of Agriculture, Department of Horticulture, \\ Samsun, Turkey
}

\begin{abstract}
Additional Index words. Lycopersicon esculentum, flowering, fruit number per cluster, mean fruit weight, fruit growth period, fruit production rate

ABstract. Determinations were made of the effect of mean daily temperature and cumulative daily light intensity related to planting date on fruiting behavior of greenhouse-grown tomato (Lycopersicon esculentum Mill.). Time to first flowering (FT), flower bud number per cluster (BN/C), fruit number per cluster (FN/C), mean fruit weight, fruit growth period (FGP), and fruit production rate (FPR) in tomato were plotted against mean daily temperature (11 to $28{ }^{\circ} \mathrm{C}$ ) and mean cumulative daily light intensity $\left(2\right.$ to $\left.8 \mathrm{MJ} \cdot \mathrm{m}^{-2} \cdot \mathrm{d}^{-1}\right)$ obtained from different planting dates. The FT was negatively related to mean daily temperature at any given mean cumulative daily light intensity. Mean cumulative daily light intensity had a negative sharp and slight curvilinear relationship to FT at lower and higher mean daily temperatures, respectively. At the highest cumulative daily light intensity, BN/C was the greatest at the lowest mean daily temperature, whereas at lower cumulative daily light intensities, $\mathrm{BN} / \mathrm{C}$ was curvilinearly related to mean daily temperature with the optimum mean daily temperature for $\mathrm{BN} / \mathrm{C}$ between 13 and $19^{\circ} \mathrm{C}$. Mean cumulative daily light intensity had a positive curvilinear relationship to $\mathrm{BN} / \mathrm{C}$ at any given mean daily temperature. $\mathrm{FN} / \mathrm{C}$ increased linearly with mean cumulative daily light intensity with a steeper slope at low mean daily temperatures. At each cumulative daily light intensity, FN/C declined curvilinearly with mean daily temperature. Mean fruit weight was curvilinearly related to mean daily temperature at all mean cumulative daily light intensities. Mean fruit weight was greatest at the highest mean cumulative daily light intensities. There was a curvilinear relationship between mean cumulative daily light intensity and FGP at all mean daily temperatures. The FGP increased curvilinearly as mean daily temperature and mean cumulative light intensity increased. There was a curvilinear increase in FPR with mean cumulative daily light intensity at any given mean daily temperatures. Mean daily temperature also had a curvilinear effect on FPR such that FPR increased up to $25^{\circ} \mathrm{C}$ for the lowest cumulative daily light intensity and $22{ }^{\circ} \mathrm{C}$ for the highest cumulative daily light intensity and declined thereafter as mean daily temperature increased. Optimum mean daily temperatures for FPR declined as mean cumulative daily light intensity rose. It can be said that the relationships produced in this study can be incorporated into the climate control and fertigation programs of greenhouse tomatoes.
\end{abstract}

The rate of crop development governs crop duration, which is of considerable importance in determining crop yields (Ellis et al., 1990). The rate of development of a plant is often sensitive to temperature and photoperiod (Atherton and Harris, 1986; Charles-Edwards et al., 1986; Ellis et al., 1990; Grimstad, 1995). The results from both experimental and theoretical studies (Ellis et al., 1990; Gent, 1986; Gent and Ma, 2000; Hadley et al., 1983a, 1983b; Monteith, 1981; Pearson et al., 1994; Peet and Willits, 1991) indicate that high temperatures (above $22{ }^{\circ} \mathrm{C}$ ) generally reduce crop yields. This is because increasing temperatures generally shorten the duration for growth relatively more than it increases the rate of growth. Furthermore, high temperatures reduce the harvest index, the proportion of dry matter allocated to crop yield, fruit set, and the rate of leaf photosynthesis and increase flower bud formation and flower drop, leaf respiration, and stomata closure (Atherton and Harris, 1986; Ellis et al., 1990; Gent, 1988).

The majority of previous quantitative studies on plant growth, development, and yield have emphasized modeling photosynthetic rates. These studies have provided an important basis for understanding the factors affecting crop photosynthesis, which in turn account for the majority of variation in yield

Received for publication 18 Apr. 2006. Accepted for publication 9 Apr. 2007. E-mail: sezginuz@omu.edu.tr. increases. The aim of plant or crop models is to describe mathematically the increase of biomass in terms of fresh weight, dry weight, volume, diameter, and plant development, particularly with reference to flowering and fruit (Liebig, 1989). Several models predict the assimilate production of tomato with reasonable accuracy (Acock, 1991; Acock et al., 1978; Bertin and Heuvelink, 1993; Charles-Edwards et al., 1986; Dan et al., 1993; DeKoning, 1994; Jones et al., 1991; Pearson, 1992; Picken et al., 1986; Schmidt, 2002).

Regression models are useful management tools for production agriculture because they are relatively easy to develop and, if carefully defined under the prevailing environmental conditions, they can accurately forecast long-term crop responses (Jovanovic and Annandale, 2000; Krug, 1985; Rosati et al., 2002a, 2002b). Moreover, plant simulation models have great potential use, but as yet few of them have left the research environment (Seligman, 1990). However, models predicting the growth period for lettuce (Lactuca sativa L.) and cauliflower (Brassica oleracea L. var. botrytis L.) have been used by growers in the United Kingdom for the last 12 years (Pearson, 1992).

To date, there has been a lack of research on the quantitative effect of a wide range of environmental factors on fruiting behavior of tomato. Hence, some developmental and yield responses to a wide range of temperature and light intensities 
obtained at different planting times were examined to determine the responses of these variables to mean daily temperature and cumulative daily light intensity.

\section{Materials and Methods}

Controlling plant environment. A series of tomato development and fruiting experiments were conducted in a suite of controlled-mean daily temperature glasshouse compartments ( size $=4 \times 8 \mathrm{~m}$ ) for 2 years. The inner six of an array of eight glasshouse compartments were used to provide a maximum set mean daily temperatures of $4,10,14,18,22$, and $26^{\circ} \mathrm{C}$ in the first year of the experiment and $6,8,12,16,20$, and $24{ }^{\circ} \mathrm{C}$ in the second year. Mean daily temperature control in the compartments was adjusted to provide heat when the mean daily temperature in the compartment dropped below the set point and the vents were opened to cool the glasshouse compartments when mean daily temperature raised more than $4{ }^{\circ} \mathrm{C}$ above the set temperature. These set temperatures resulted in the measured mean daily temperatures given in Table 1 . The measured mean daily temperatures were used in multiple regression analysis.

Plant cultivation. Seeds of the indeterminate tomato cultivar 'Counter' were sown in modular seed trays containing 228 cells $(2 \times 2 \mathrm{~cm})$ filled with commercial peat-based compost (Fisons 2; Proculture Plants Ltd., Badsey-Evesham, UK). The seed trays were kept in a glasshouse compartment maintained at $22{ }^{\circ} \mathrm{C}$. After the seedlings emerged, the seed trays were placed in a different compartment with a mean daily temperature of $20^{\circ} \mathrm{C}$. Sowing, transplanting, and planting dates for each experiment are given in Table 1. Three different planting times were used in each year to create different natural mean cumulative daily light intensity conditions. Three weeks after emergence, plants were repotted into 15 -cm-diameter plastic pots containing Fisons M2 commercial compost. After the plants reached the fifth true leaf stage, they were planted into Fisons Gro-Bags (Proculture Plants Ltd.) containing a peat compost, spaced at a distance of $50 \mathrm{~cm}$ between the rows and $35 \mathrm{~cm}$ within rows,

Table 1. Mean daily temperature and mean cumulative daily light intensity in greenhouse compartments for various sowing, transplanting, and planting dates used in the study of fruiting behavior in tomato.

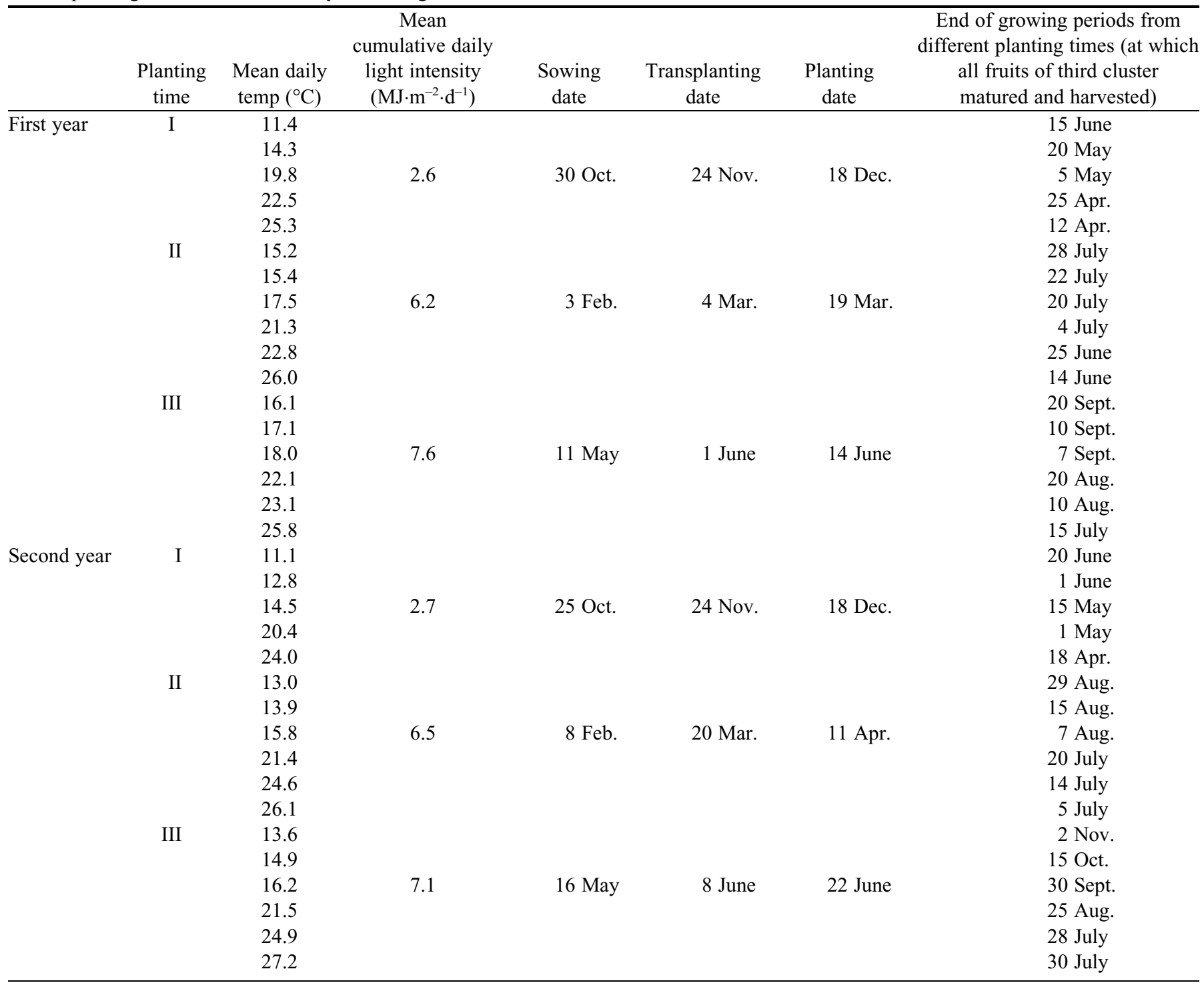


giving a plant density of 6 plants $/ \mathrm{m}^{2}$. Three seedlings were planted into each growbag. Twelve growbags and a total of 36 plants were placed into each growth compartment with different mean daily temperature for each planting time. Plants were grown as a single stem, trained vertically, and supported by strings. Side shoots of the plants were removed at weekly intervals. At the stage of fruit set, the plants were tapped every $3 \mathrm{~d}$ to aid pollination. Plants were irrigated on four occasions each day with a standard nutrient feed (Sangral SS 112; Sinclair Horticulture Ltd., Lincoln, UK), diluted to give a concentration of $0.2 \mathrm{~g} \cdot \mathrm{L}^{-1}$ nitrogen, $0.2 \mathrm{~g} \cdot \mathrm{L}^{-1}$ phosphorous, and $0.4 \mathrm{~g} \cdot \mathrm{L}^{-1}$ potassium, to provide a conductivity of $1.6 \mathrm{dS} \cdot \mathrm{m}^{-1}$ and $\mathrm{pH}$ of 6.5 using a trickle irrigation system.

Mean CUMUlative daILY Light INTENSITY AND MEAN DaILY TEMPERATURE MEASUREMENTS. The mean daily temperature in each compartment was recorded at intervals of 15 min using a Combine data logger (Delta-T Devices Ltd., Cambridge, UK), and daily mean daily temperatures were determined over the average of these daily recordings and were regarded as actual daily mean daily temperatures in the compartments during the experimental period (Table 1). In all regression analysis, data of mean daily temperature for each experiment were used. Mean daily temperature values used in the analysis were the actual mean daily temperatures rather than the set temperatures. Photosynthetically active radiation $(P A R)$ was recorded using a tube and a KIPP solarimeter (Scecinz, Monteith, and Ds Santos, Harpenden, UK) located above the plants. The tube and KIPP solarimeters were connected to a data logger (SkyeModel 3; Delta-T Devices Ltd.). Mean cumulative daily light intensity data from the KIPP solarimeter recorded by means of a data logger were used as $P A R$ for different parameters used in the analysis as mean cumulative daily light intensity averaged over each planting time (Table 1). Because the three planting times were repeated in the second year, a total of 36 mean daily temperatures and 36 different mean cumulative daily light intensities were obtained. The six different growth compartments had different mean daily temperatures and different mean cumulative daily light intensities because of changing growth periods. Although mean cumulative daily light intensity values were different as a result of differing plant growth periods, they were similar to each other (Table 1). Therefore, mean cumulative daily light intensity values calculated by taking the average of mean cumulative daily light intensities from different compartments for each planting time (six different mean cumulative daily light intensities for six different planting times) were used in multiple regression analysis (Table 1). Moreover, two different mean daily temperature values (under $11^{\circ} \mathrm{C}$ ) out of all the planting times of the study were excluded from the analysis because no growth was obtained at these mean daily temperatures. Therefore, 34 mean daily temperatures and 34 matching mean cumulative daily light intensity values were used in the analysis (Table 1).

EQUATION DRIVING, EXPERIMENTAL DESIGN, AND DATA ANALYSIS. The experimental design was a randomized complete block with three replications and three plants in each replication (Table 1). Data obtained from all the planting dates were gathered to carry out multiregression analysis. Mean daily temperature and mean cumulative daily light intensity were related to the following plant development variables: days to first flowering (FT), flower bud number per cluster (BN/C), fruit number per cluster (FN/C), mean fruit weight (MFW), fruit growth period (FGP), and fruit production rate [FPR (grams per day)]. Data were collected until all of the third cluster on the plants matured and were harvested. Ending time of the experiment was regarded as the time at which all the fruits of the third cluster on the plants matured and were harvested (Table 1). Multiple regression analysis (forward selection method) was performed with Excel (Microsoft Corp., Redmond, WA) and PC-SAS (release 6.03; SAS Institute, Cary, NC) following the procedure of Gomez and Gomez (1984). Curve fitting processes were continued until the least sum of squares of residuals was obtained.

All the equations were derived by plotting the data as mean values (34 mean daily temperature values for each parameter) derived from a total of nine plants (three replicate and three plants for each replicate) against the data sets of mean daily temperature and mean cumulative daily light intensity combined for all growing periods (Table 1). To determine the most suitable equation, multiple regression analysis for all the variables used in the study was continued until the highest regression coefficient $\left(\mathrm{r}^{2}\right)$ with the least sum of squares for residuals were obtained. The three-dimensional graphs were drawn using Slide-Write Package Program 2.0 (Advanced Graphics Software, Carlsbad, CA).

\section{Results and Discussion}

Time to First Flowering. The regression equation with the lowest sum of squares of the residuals between time to flowering (FT) and mean daily temperature $\left[\mathrm{T}\left({ }^{\circ} \mathrm{C}\right)\right]$ and mean cumulative daily light intensity $\left[\mathrm{L}\left(\mathrm{MJ} \cdot \mathrm{m}^{-2} \cdot \mathrm{d}^{-1}\right)\right]$ was

$$
\begin{aligned}
& \mathrm{FT}=183.47-4.19[\mathrm{~T}]+0.0096\left[\mathrm{~T}^{2} \mathrm{~L}\right]-1.58\left[\mathrm{~L}^{2}\right] \\
& \mathrm{SE}[8.92] * * *[0.57]^{* * *}[0.0025]^{* * *}[0.107]^{* *} \\
& \mathrm{r}^{2}=0.96 * * *(* *: P<0.01, * * *: P<0.001) .
\end{aligned}
$$

Where SE represents standard errors of coefficients. As seen from Eq. [1], most of the variation (96\%) in FT was explained by mean daily temperature and mean cumulative daily light intensity. This relationship incorporates both linear and curvilinear responses as well as complex interactions between mean daily temperature and mean cumulative daily light intensity. Figure 1 shows that FT was a negative linear and curvilinear function of mean daily temperature at both high and low mean cumulative daily light intensities, respectively. Mean cumulative daily light intensity also had a sharp and slight negative curvilinear effect on FT at low and high mean daily temperatures, respectively (Fig. 1). In general, FT declined with increasing mean cumulative daily light intensity and mean daily temperature. FT was most responsive to mean cumulative daily light intensity (Fig. 1). Therefore, FT declined much more sharply with mean cumulative daily light intensity compared with mean daily temperature (Fig. 1). It decreased approximately linearly from 115 to $130 \mathrm{~d}$ at $2 \mathrm{MJ} \cdot \mathrm{m}^{-2} \cdot \mathrm{d}^{-1}$ to 40 to $45 \mathrm{~d}$ at $8 \mathrm{MJ} \cdot \mathrm{m}^{-2} \cdot \mathrm{d}^{-1}$. There was only a slight effect of mean daily temperature. FT decreased by 5 to $15 \mathrm{~d}$ as mean daily temperature increased from 11 to $28{ }^{\circ} \mathrm{C}$ with a greater decrease at high mean cumulative daily light intensity. The highest FT (118 d) was obtained with low mean cumulative daily light intensity and low mean daily temperature $\left(11^{\circ} \mathrm{C}\right)$. The lowest FT (39 d) was from the fruits of the plants grown with the highest mean cumulative daily light intensity and mean daily temperature $\left(26^{\circ} \mathrm{C}\right)$. 


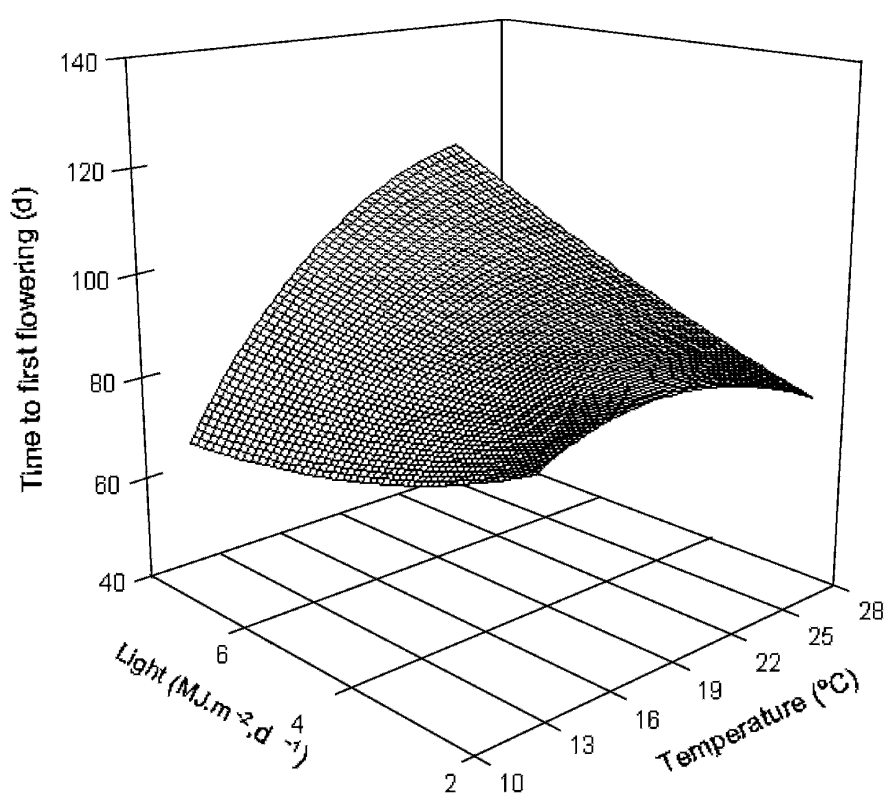

Fig. 1. Changes in time to first flowering with mean daily temperature and mean cumulative daily light intensity in tomato. The plane was fitted by multiple regression analysis $\left(r^{2}=0.96\right)$.

The rate of crop development governs plant growth period, which is of considerable importance in determining crop yields (Ellis et al., 1990; Hadley et al., 1983b). Moreover, studies on a number of crops have shown that low mean cumulative daily light intensity also considerably delays time to flowering (Atherton and Harris, 1986; Cockshull et al., 1992; Dileman and Heuvelink, 1992; Gent, 1986). These results are in accordance with results from the present study. It was also reported that mean daily temperature affects times from sowing to flowering in three distinct ways: 1) there may be a specific cold-mean daily temperature hastening of flowering; 2) over a wide range of mean daily temperatures, time to first flowering declines with increasing mean daily temperature to an optimum at which flowering is most rapid; and 3) at supraoptimal (stressful) mean daily temperatures, flowering is progressively delayed as mean daily temperature increases (Roberts et al., 1985).

BUd NUMBER PER CLUSTER. The regression equation with the lowest sum of squares of the residuals between mean BN/C and mean $\mathrm{T}\left({ }^{\circ} \mathrm{C}\right)$ and mean $\mathrm{L}\left(\mathrm{MJ} \cdot \mathrm{m}^{-2} \cdot \mathrm{d}^{-1}\right)$ was

$$
\begin{gathered}
\mathrm{BN} / \mathrm{C}=9.74-6.85[\mathrm{~L}]-0.16\left[\mathrm{~L}^{2} \mathrm{~T}\right]+1.18\left[\mathrm{~L}^{2}\right] \\
+0.68[\mathrm{TL}]-0.019\left[\mathrm{~T}^{2} \mathrm{~L}\right]+0.003\left[\mathrm{~L}^{2} \mathrm{~T}^{2}\right] \\
\mathrm{SE}[0.82] * * *[1.41] * * *[0.02]^{* * *}[0.21] * * * \\
\quad[0.15]^{* * *}[0.004] * * *[0.0006] * * * \\
\mathrm{r}^{2}=0.93 * * *(* * *: P<0.001) .
\end{gathered}
$$

Equation [2] explained a reasonably high proportion of variance. $\mathrm{BN} / \mathrm{C}$ was most responsive to mean daily temperature (Fig. 2). At low mean cumulative daily light intensity, a maximum bud number of eight was observed at $17^{\circ} \mathrm{C}$ with a decrease to 7.3 and 6.6 at the lowest and highest mean daily temperature. At high mean cumulative daily light intensities, $\mathrm{BN} / \mathrm{C}$ declined approximately linearly with mean daily temperature from 12 buds at $11^{\circ} \mathrm{C}$ and 11 to seven buds at $28^{\circ} \mathrm{C}$.

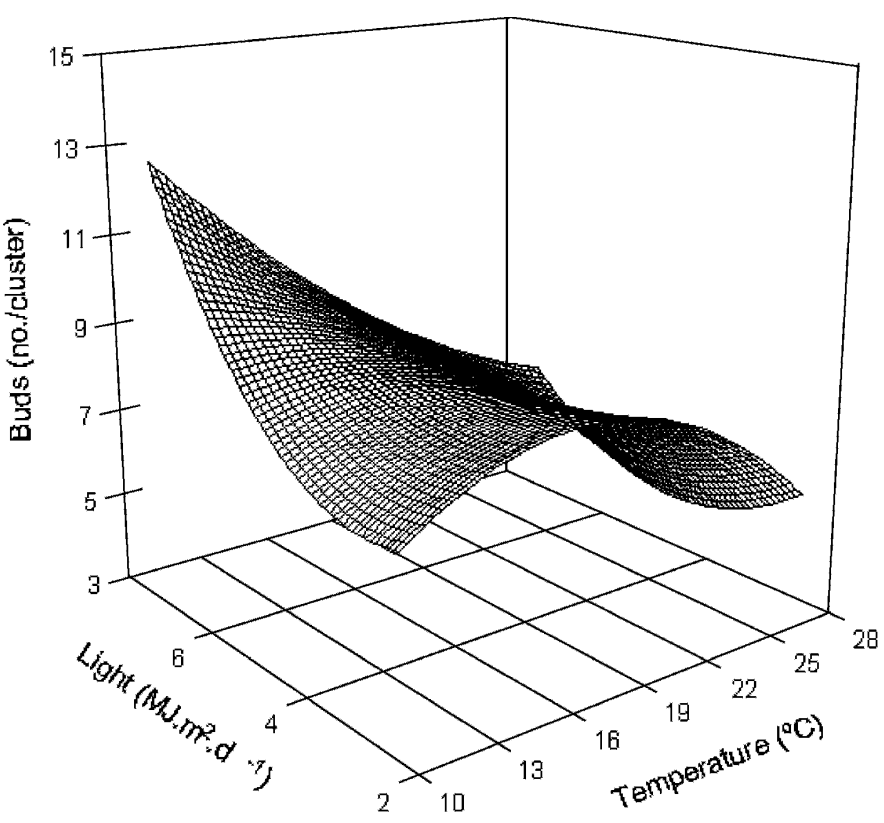

Fig. 2. Changes in flower bud number per cluster in tomato with mean daily temperature and mean cumulative daily light intensity. The plane was fitted by multiple regression analysis $\left(r^{2}=0.93\right)$.

At any given mean daily temperature, $\mathrm{BN} / \mathrm{C}$ increased curvilinearly with mean cumulative daily light intensity (Fig. 2). Atherton and Harris (1986) stated that the ability of plants to maintain normal development of the flower buds appears to be related to the availability of assimilates. In winter, when assimilation rates are low, flower bud development is often poor. It was also reported that under limited mean cumulative daily light intensity conditions, flower bud occurrence of eggplant (Solanum melongena L.) is poor and this also results in high flower abortion as well as reduced flower bud occurrence through concentration of low assimilates (Gent, 1988; Passam and Khah, 1992).

Fruit NUMBer PER CLUSTER. The regression equation with the lowest sum of squares of the residuals between mean FN/C and mean $\mathrm{T}\left({ }^{\circ} \mathrm{C}\right)$ and mean $\mathrm{L}\left(\mathrm{MJ} \cdot \mathrm{m}^{-2} \cdot \mathrm{d}^{-1}\right)$ was

$$
\begin{aligned}
& \mathrm{FN} / \mathrm{C}=4.25+0.79[\mathrm{~L}]-0.0005\left[\mathrm{~T}^{2} \mathrm{~L}\right] \\
& \mathrm{SE}[0.196]^{* * *}[0.043] * * *[0.00006]^{* * *} \\
& \mathrm{r}^{2}=0.92 * * *(* * *: P<0.001) .
\end{aligned}
$$

It can also be seen from Eq. [3] that both mean daily temperature and mean cumulative daily light intensity had a curvilinear and linear effect on FN/C, respectively, as well as an interactive effect on $\mathrm{FN} / \mathrm{C}$. In contrast to bud number, fruit number was more responsive to mean cumulative daily light intensity than to mean daily temperature (Fig. 3). FN/C increased with mean cumulative daily light intensity from $\approx 4$ to $\approx 10$ fruit with a greater slope at low than high mean daily temperatures. Increasing mean daily temperature decreased fruit number curvilinearly from $\approx 10$ to $\approx 7$ under high mean cumulative daily light intensity. Under low mean cumulative daily light intensity, FN/C declined with a slight curvilinear slope.

The highest $\mathrm{FN} / \mathrm{C}$ was obtained from the plants grown at lower mean daily temperatures with the highest mean 


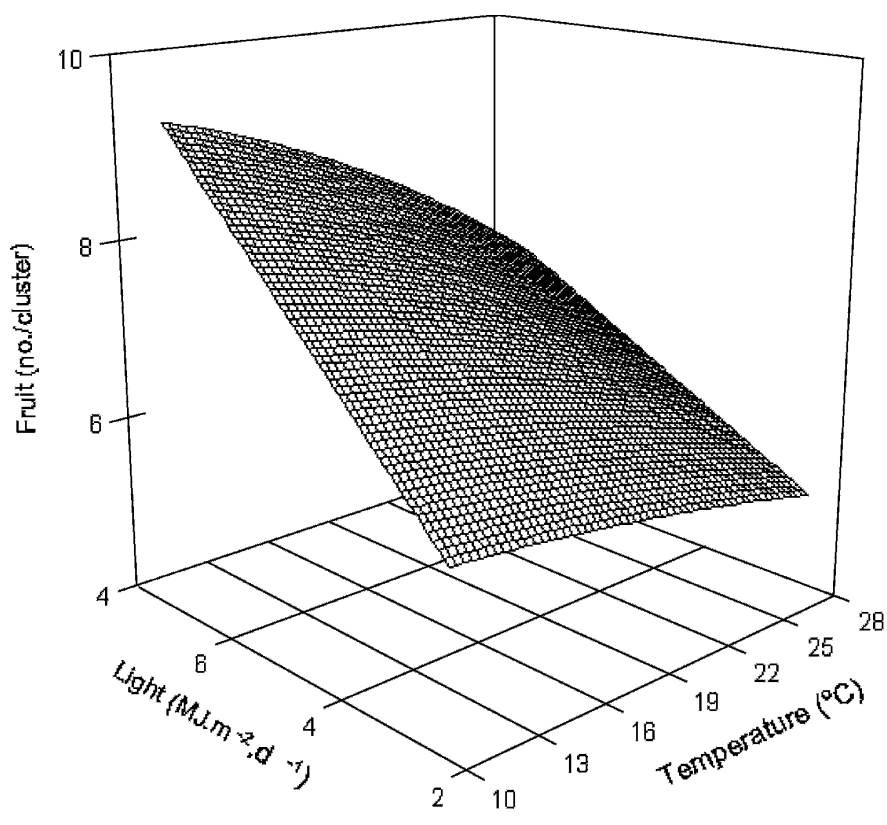

Fig. 3. Changes in fruit number per cluster in tomato with mean daily temperature and mean cumulative daily light intensity. The plane was fitted by multiple regression analysis $\left(r^{2}=0.92\right)$.

cumulative daily light intensity, whereas the lowest $\mathrm{FN} / \mathrm{C}$ was obtained at the highest mean daily temperature with the lowest mean cumulative daily light intensity. Several studies have shown that fruit number per cluster in tomato and per plant in some vegetable crops increases with increasing mean daily temperature up to an optimum depending on plant species and declines at higher mean daily temperatures (e.g., Aung, 1976; Calvert, 1972; Cockshull et al., 1992; DeKoning, 1994; Dorais et al., 1991; Gent, 1988; Passam and Khah, 1992; Pearson, 1992; Peet and Bartholemew, 1996). Pearson (1992) also reported that fruit number per cluster in tomato was positively related to increasing mean cumulative daily light intensity. In addition to this, Dorais et al. (1991) indicated that higher mean cumulative daily light intensity raised total number of fruits in tomato compared with lower mean cumulative daily light intensities.

Mean fRuit Weight. The regression equation with the lowest sum of squares of the residuals between MFW (grams) and mean $\mathrm{T}\left({ }^{\circ} \mathrm{C}\right)$ and mean $\mathrm{L}\left(\mathrm{MJ} \cdot \mathrm{m}^{-2} \cdot \mathrm{d}^{-1}\right)$ was

$$
\begin{aligned}
& \mathrm{MFW}=142.69-5.37[\mathrm{~T}]-64.18[\mathrm{~L}]-0.045\left[\mathrm{LT}^{2}\right] \\
& +4.29[\mathrm{LT}]+6.19\left[\mathrm{~L}^{2}\right]-0.28\left[\mathrm{~L}^{2} \mathrm{~T}\right] \\
& \mathrm{SE}[51.20]^{* *}[2.54]^{* *}[25.53]^{* *}[0.01] * * * \\
& \quad[1.29]^{* * *}[2.67]^{* *}[0.13]^{*} \\
& \mathrm{r}^{2}=0.92 * * *(*: P<0.05, *: P<0.01, * * *: P<0.001) .
\end{aligned}
$$

It can be seen from Eq. [4], mean daily temperature and mean cumulative daily light intensity had a curvilinear effect on MFW as well as their interactive effect on MFW. Eq. [4] had a high degree of determination (92\%) and can be used to predict MFW from mean daily temperature and mean cumulative daily light intensity. Mean fruit weight decreased with mean daily temperature and increased with mean cumulative daily light intensity to a plateau of $\approx 90 \mathrm{~g}$ at 6 to $8 \mathrm{MJ} \cdot \mathrm{m}^{-2} \cdot \mathrm{d}^{-1}$ and 12 to
$15{ }^{\circ} \mathrm{C}$. The response to mean daily temperature was steepest at high mean daily temperature and high mean cumulative daily light intensity, and the response to mean cumulative daily light intensity was steepest at low mean cumulative daily light intensity and low mean daily temperature (Fig. 4). Figure 4 shows that MFW was a curvilinear function of mean daily temperature at any given mean cumulative daily light intensity and a curvilinear function of mean cumulative daily light intensity at any given mean daily temperatures. There was a curvilinear increase in MFW with mean daily temperature up to $22.5^{\circ} \mathrm{C}$ at the lowest mean cumulative daily light intensity and $\approx 16^{\circ} \mathrm{C}$ at the highest cumulative daily mean cumulative daily light intensity and a decline at higher mean daily temperatures at all mean cumulative daily light intensities.

At the lowest mean cumulative daily light intensity, MFW increased with mean daily temperature up to $22.5^{\circ} \mathrm{C}$ and declined thereafter. The highest MFW, $93 \mathrm{~g}$, was obtained at $\approx 16{ }^{\circ} \mathrm{C}$ with the highest mean cumulative daily light intensity, whereas the lowest MFW, $42 \mathrm{~g}$, was obtained at the lowest mean cumulative daily light intensity and mean daily temperature. Higher mean cumulative daily light intensities also resulted in higher mean fruit weight $(P<0.01)$. High mean cumulative daily light intensities were reported to result in higher fruit weight in tomato than lower ones (DeKoning, 1994; Dorais et al., 1991; Pearson, 1992). Others reported curvilinear relationships between final fruit weight of tomato and temperature (Atherton and Harris, 1986; Cockshull et al., 1992; DeKoning, 1994; Gent, 1988; Pearson, 1992) reported that there was a curvilinear relationship between final fruit weight in tomato and mean daily temperature. They also reported that different plant processes have different mean daily temperature optima and the interaction between these processes can also result in changed optima. All these results are in accordance with the results of mean fruit weight from the present study. On the other hand, potential fruit weight in tomato at maturity is

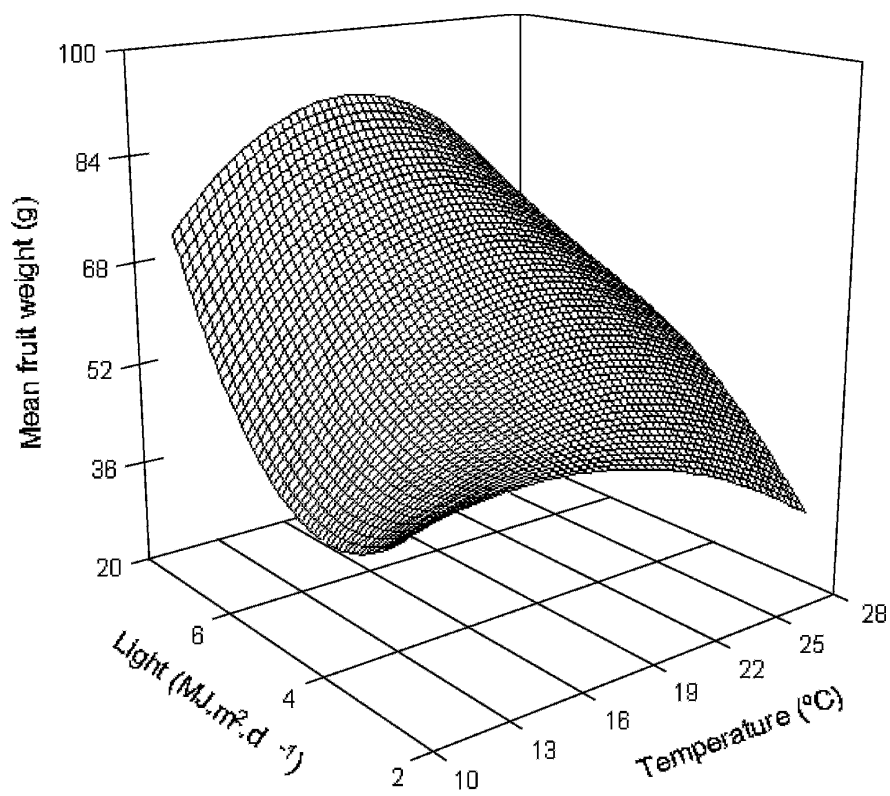

Fig. 4. The effects of mean daily temperature and mean cumulative daily light intensity on mean fruit weight in tomato. The plane was fitted by multiple regression analysis $\left(r^{2}=0.92\right)$. 
determined by the sink size developed at fruit initiation and sink activity during fruit growth (DeKoning, 1994).

FruIt GROWTH PERIOD. The regression equation with the lowest sum of squares of the residuals between FGP (days) and mean $\mathrm{T}\left({ }^{\circ} \mathrm{C}\right)$ and mean $\mathrm{L}\left(\mathrm{MJ} \cdot \mathrm{m}^{-2} \cdot \mathrm{d}^{-1}\right)$ was

$\mathrm{FGP}=249.07-13.96[\mathrm{~T}]+0.03\left[\mathrm{~L}^{2} \mathrm{~T}\right]+0.24\left[\mathrm{~T}^{2}\right]-1.01\left[\mathrm{~L}^{2}\right]$

$\mathrm{SE}[20.47]^{* *}[2.39]^{* * *}[0.013]^{* *}[0.006]^{* * *}[0.26]^{* * *}$

$\mathrm{r}^{2}=0.94 * * *(* *: P<0.01, * * *: P<0.001)$.

FGP was most responsive to low mean daily temperature, increasing rapidly from a minimum of $\approx 40 \mathrm{~d}$ at 22 to $25^{\circ} \mathrm{C}$ to a maximum of $115 \mathrm{~d}$ at $11{ }^{\circ} \mathrm{C}$. At any given mean daily temperature, this period decreased by $\approx 15 \mathrm{~d}$ as mean cumulative daily light intensity increased from 2 to $8 \mathrm{MJ} \cdot \mathrm{m}^{-2} \cdot \mathrm{d}^{-1}$ (Fig. 5). Figure 5 shows that FGP declined curvilinearly as mean cumulative daily light intensity increased from the lowest to the highest point at all mean daily temperatures examined in the present study. FGP also declined curvilinearly as mean daily temperature increased at any given mean cumulative daily light intensity.

Pearson (1992), Cockshull et al. (1992), and DeKoning (1994) stated a linear relationship between fruit development in tomato and mean cumulative daily light intensity. Nothmann (1986) reported that low mean daily temperatures cause slow fruit development in eggplant from the same family as the tomato. It was also reported that for plants such as tomato and pepper (Capsicum annuum L.), fruit development rate increases with increasing mean daily temperatures and fruit growth period decreases accordingly (Atherton and Harris, 1986; DeKoning, 1994; Gent, 1988). Moreover, Bakker (1990) reported that the average fruit maturation period of eggplant in fall was 4 weeks, $\approx 1$ week shorter than during spring as a result of higher mean daily temperatures. In addition, fruit growth rate was reported to be influenced by mean daily

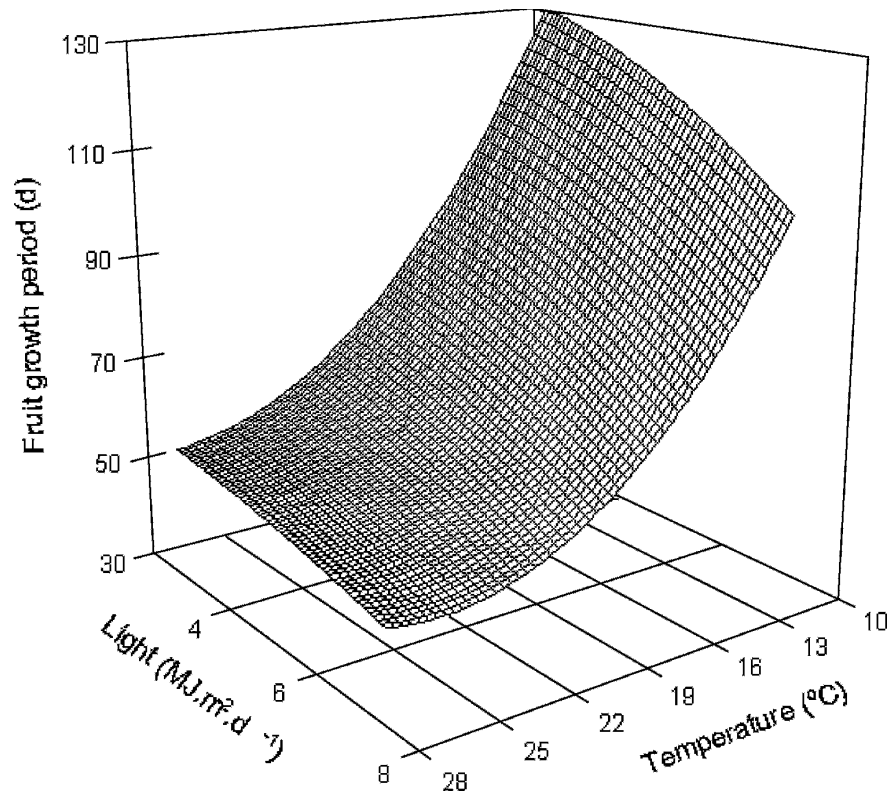

Fig. 5. The effects of mean daily temperature and mean cumulative daily light intensity on fruit growth period in tomato. The plane was fitted by multiple regression analysis $\left(r^{2}=0.94\right)$. temperature affecting the rates of respiration and starch synthesis in the fruit and changing assimilate import by fruit mean daily temperature (Ho and Hewitt, 1986; Marcelis and Heuvelink, 1999).

Fruit production rate. The regression equation with the lowest sum of squares of the residuals between FPR (grams per day) and mean $\mathrm{T}\left({ }^{\circ} \mathrm{C}\right)$ and mean $\mathrm{L}\left(\mathrm{MJ} \cdot \mathrm{m}^{-2} \cdot \mathrm{d}^{-1}\right)$ was

$\mathrm{FPR}=101.46-77.53[\mathrm{~L}]+5.78\left[\mathrm{~L}^{2}\right]+3.50[\mathrm{TL}]-0.079\left[\mathrm{~T}^{2} \mathrm{~L}\right]$

$\mathrm{SE}[21.01]^{* * *}[12.14]^{* * *}[1.04]^{* * *}[0.82]^{* * *}[0.02]^{* * *}$

$\mathrm{r}^{2}=0.93 * * *(* * *: P<0.001)$.

It can also be seen from Eq. [6] that mean daily temperature and mean cumulative daily light intensity were curvilinearly related to FPR. There was a significant statistical interaction between mean daily temperature and mean cumulative daily light intensity on FPR. Mean daily temperature had a significant effect $(P<0.01)$ on FPR. Higher mean daily temperatures up to an optimum resulted in higher FPR at any given mean cumulative daily light intensity. This increase was sharper at lower mean cumulative daily light intensity (Fig. 6). For the plants grown with the lowest mean cumulative daily light intensity, FPR increased with increasing mean daily temperature up to $25.0^{\circ} \mathrm{C}$ and declined thereafter (Fig. 6). A similar but steeper increase was observed for the plants grown with the highest mean cumulative daily light intensity with increasing mean daily temperature up to $22.0{ }^{\circ} \mathrm{C}$ and declined as mean daily temperature increased beyond that point. However, the decline in FPR was sharper at higher mean cumulative daily light intensities than it was at lower ones. Optimum mean daily temperatures for FPR declined as mean cumulative daily light intensity rose such as optimum mean daily temperature for FPR was $25.0^{\circ} \mathrm{C}$ at the lowest mean cumulative daily light intensity, whereas it was $22.0^{\circ} \mathrm{C}$ at the highest mean cumulative daily light intensity. There was a clear slight curvilinear increase in

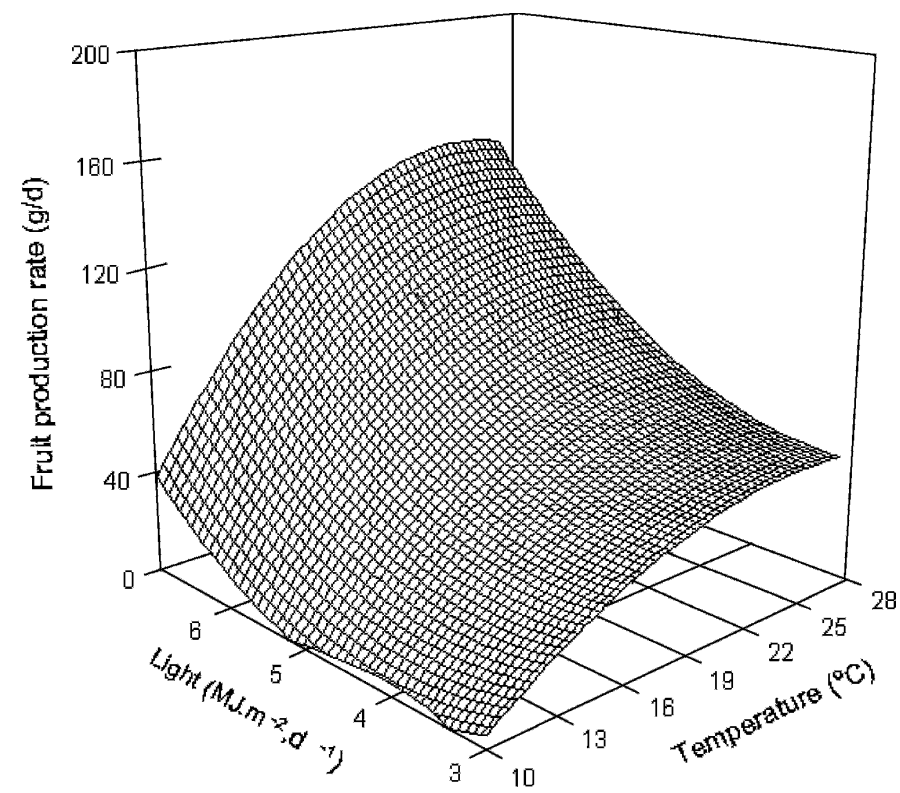

Fig. 6. The effects of mean daily temperature and mean cumulative daily light intensity on fruit production rate in tomato. The plane was fitted by multiple regression analysis $\left(r^{2}=0.93\right)$. 
FPR with increasing mean cumulative daily light intensity at the mean daily temperatures above $11^{\circ} \mathrm{C}$.

The combination of $22.0{ }^{\circ} \mathrm{C}$ and the highest mean cumulative daily light intensity gave the highest FPR. The lowest FPR was obtained from the plants grown with a combination of the lowest mean cumulative daily light intensity and the lowest mean daily temperature. The total yield of tomato was also reported to increase with mean cumulative daily light intensity (Dorais et al., 1991). Cockshull et al. (1992) also indicated a relationship between mean cumulative daily light intensity and yield of tomato. They found that a $1 \%$ increase in mean cumulative daily light intensity throughout the growing season produced approximately a $1 \%$ increase in yield for the mean cumulative daily light intensities under saturating mean cumulative daily light intensity for photosynthesis and that increased yield was determined largely by an increase in mean fruit size. In addition, Fitter and Hay (1987) stated that one of the most important determinants of plant yield is the duration of crop growth. The longer the crop duration, the more mean cumulative daily light intensity energy is intercepted and therefore the more yield components could be produced. In parallel with this view, it was reported that higher mean daily temperatures generally reduce crop yields. This is because increasing mean daily temperatures generally shortens the duration for growth relatively more than it increases the rate of growth (Atherton and Harris, 1986; DeKoning, 1994; Ellis et al., 1990; Fitter and Hay, 1987; Heuvelink and Bertin, 1994; Monteith, 1981). In the present study, it was found that higher fruit production rate in tomato was mostly the result of increased MFW and decreased fruit growth period at optimum mean daily temperature and mean cumulative daily light intensities. Therefore, these explanations are in parallel with the results of the present study.

In conclusion, it can be said that the relationships produced in this study can be incorporated into the climate control and fertigation programs of greenhouse tomatoes. Further experimental and commercial validation of the equations produced in this study is needed, especially with the crop grown under a light environment that is higher than those used in this study. Further applications of the equations from the present study could be through integration into crop models for computerized climate control in greenhouses. Clearly, this is the ultimate goal of many researchers, software developers, and growers, and the data gathered in this study may partially contribute to this end, especially because it covers fruiting responses of tomato over such a substantial range of environmental conditions.

\section{Literature Cited}

Acock, B. 1991. Modelling canopy photosynthetic response to carbon dioxide, light interception, temperature and leaf traits, p. 41-55. In: Boote, H.J. and R.S. Loomis (eds.). Modelling crop photosynthesis from biochemistry to canopy. 19th ed. Crop Sci. Soc. Amer., CSSA Special Publication, Madison, WI.

Acock, B., D.A. Charles-Edwards, D.J. Fitter, D.W. Hand, L.J. Ludwig, J. Wilson-Warren, and A.C. Withers. 1978. The contribution of leaves from different levels within a tomato crop to canopy net photosynthesis: An experimental examination of two canopy models. J. Expt. Bot. 29:815-827.

Atherton, J.G. and G.P. Harris. 1986. Flowering, p. 167-200. In: Atherton, J.G. and J. Rudich (eds.). The tomato crop. Chapman and Hall, London.

Aung, L.H. 1976. Effects of photoperiod and temperature on vegetative and reproductive responses of Lycopersicon esculentum Mill. J. Amer. Soc. Hort. Sci. 101:348-360.
Bakker, J.C. 1990. Effects of day and night humidity and yield quality of glasshouse eggplant. J. Hort. Sci. 65:747-753.

Bertin, N. and E. Heuvelink. 1993. Dry matter production in a tomato crop: Comparison of two simulation models. J. Hort. Sci. 68:9951011.

Calvert, A. 1972. Effect of day and night temperatures and carbon dioxide enrichment on yield of glasshouse tomatoes. J. Hort. Sci. 47:231-247.

Charles-Edwards, A.D., D. Doley, and G.M. Rimmington. 1986. Modelling plant growth and development. Academic Press, Sydney, New York, London.

Cockshull, K.E., C.J. Graves, and C.R.J. Cave. 1992. The influence of shading on yield of glasshouse tomatoes. J. Hort. Sci. 67:11-24.

Dayan, E., H. Van Keulen, J.W. Jones, and H. Challa. 1993. Development, calibration and validation of a greenhouse tomato growth model. I. Description of the model. Agr. Systems 43: $165-183$

DeKoning, A.N.M. 1994. Development and dry matter distribution in glasshouse tomato. A quantitative approach. Agricultural University, Wageningen, The Netherlands, thesis.

Dileman, J.A. and E. Heuvelink. 1992. Factors affecting the number of leaves preceding the first inflorescence in tomato. J. Hort. Sci. 67:1-10.

Dorais, M., G. Andre, and M.J. Trudel. 1991. Annual greenhouse tomato production under sequential intercropping system using supplemental light. Scientia Hort. 45:225-234.

Ellis, R.H., P. Hadley, E.H. Roberts, and R.J. Summerfield. 1990. Quantitative relations between temperature and crop development and growth, p. 85-115. In: Jackson, M., B.V. Ford-Lloyd, and M.L. Parry (eds.). Climatic change and plant genetic resources. Belhaven Press, London, New York.

Fitter, A.H. and R.K.M. Hay. 1987. Environmental physiology of plants. 2nd ed. Academic Press, London.

Gent, M.P.N. 1986. Carbohydrate level and growth of tomato plants. II. The effects of irradiance and temperature. Plant Physiol. 81: 1075-1079.

Gent, M.P.N. 1988. Effect of diurnal temperature variation on early yield and fruit size of greenhouse tomato. Appl. Agr. Res. 3:257-263.

Gent, M.P.N. and Y.Z. Ma. 2000. Growth and mineral nutrition of tomato seedlings under diurnal temperature variation of the root and shoot. Crop Sci. 40:1629-1636.

Gomez, K.A. and A.A. Gomez. 1984. Statistical procedures for agricultural research. 2nd ed., Wiley, Singapore.

Grimstad, S.O. 1995. Low temperature pulse affects growth and development of young cucumber and tomato plants. J. Hort. Sci. 70:75-80. Hadley, P., E.H. Roberts, R.J. Summerfield, and F.R. Minchen. 1983a. A quantitative model of reproductive development in cowpea [Vigna unguiculata (L.) Walp.] in relation to photoperiod and temperature, and implications for screening germplasm. Ann. Bot. (Lond.) 51: 531-543.

Hadley, P., R.J. Summerfield, and E.H. Roberts. 1983b. Effects of temperature and photoperiod on reproductive development of selected grain legume crops, p. 19-41. In: Jones, D.G. and D.R. Devies (eds.). Temperate legumes: Physiology, genetics and nodulation. Pitman, London.

Heuvelink, E. and N. Bertin. 1994. Dry matter partitioning in a tomato crop: Comparison of two simulation models. J. Hort. Sci. 69:885-903.

Ho, L.C. and J.D. Hewitt. 1986. Fruit development, p. 661. In: Atherton, J.G. and J. Rudich (eds.). The tomato crop. Scientific basis for development. Chapman and Hall, London, New York.

Jones, J.W., E. Dan, L.H. Allen, H. van Keulen, and H. Challa. 1991. A dynamic tomato growth and yield model (TOMGRO). Trans. Amer. Soc. Agr. Eng. 34:663-672.

Jovanovic, N.Z. and J.G. Annandale. 2000. Crop growth model parameters of 19 summer vegetable cultivars for use in mechanistic irrigation scheduling models. Water SA 26:67-76.

Krug, H. 1985. Growth models for production planning. Acta Hort. 174:241-246. 
Liebig, H.P. 1989. Models to predict crop growth. Acta Hort. 248: 55-68.

Marcelis, L.F.M. and E. Heuvelink. 1999. Modelling fruit set, fruit growth and dry matter partitioning. Proceedings of the fifth international symposium on modelling in fruit research and orchard management. Acta Hort. 499:39-49.

Monteith, J.L. 1981. Climate variation and the growth of crops. Q. J. R. Meteorol. Soc. 107:743-774.

Nothmann, J. 1986. Fruiting of eggplant in a mild winter climate. Acta Hort. 191:237-246.

Passam, H.C. and E.M. Khah. 1992. Flowering, fruit set and fruit and seed development in two cultivars of aubergine (Solanum melongena L.) grown under plastic cover. Scientia Hort. 51:179-185.

Pearson, S. 1992. Modeling the effect of temperature on the growth and development of horticultural crops. University of Reading, Reading, UK, $\mathrm{PhD}$ thesis.

Pearson, S., P. Hadley, and W.E. Wheldon. 1994. A model of the effects of temperature on the growth and development of cauliflower (Brassica oleracea L. botrytis). Scientia Hort. 59:91-106.

Peet, M.M. and M. Bartholemew. 1996. Effect of night temperature on pollen characteristics, growth, and fruits set in tomato. J. Amer. Soc. Hort. Sci. 121:514-519.
Peet, M.M. and D.H. Willits. 1991. Tomato fruit cracking: Cultural, environmental, developmental and genetics pieces of the puzzle. HortScience 26(6):682 (abst).

Picken, A.J.F., K. Stewart, and D. Klapwick. 1986. Germination and vegetative development, p. 167-200. In: Atherton, J.G. and J. Rudick (eds.). The tomato crop. Chapman and Hall, London.

Roberts, E.H., P. Hadley, and R.J. Summerfield. 1985. Effects of temperature and photoperiod on flowering in chickpeas (Cicer arietinum, L.). Ann. Bot. (Lond.) 55:881-892.

Rosati, A., T.M. Dejong, and G. Esparza. 2002a. Physiological basis for light use efficiency models. Acta Hort. 584:89-94.

Rosati, A., A.J. Escobar-Gutierrez, and I.G. Burns. 2002b. First attempt to simulate the response of eggplant crops to N supply: A means to optimise $\mathrm{N}$ fertilisation. Acta Hort. 571:137-142.

Schmidt, U. 2002. Modelling of stomatal conductance as a variable for environmental control in greenhouses. Acta Hort. 593: 227-234.

Seligman, N.G. 1990. The crop model record: Promise or poor show, p. 249-263. In: Rabbinge, R., J. Goudriaan, H. Van Keulen, F.W.T. Penning de Vries, and H.H. van Laar (eds.). Theoretical production ecology: Reflections and prospects. Pudoc, Wageningen, The Netherlands. 